\title{
UPAYA PENINGKATAN KESEHATAN LANJUT USIA MELALUI PROGRAM PELATIHAN SENAM LANSIA BUGAR
}

\author{
Faridah \\ Prodi D III Keperawatan STIKes Baiturrahim Jambi \\ email: faridah_rty@yahoo.co.id
}

\begin{abstract}
Elderly Health Efforts are basic and comprehensive plenary health efforts in the field of elderly health which which promotive, preventive, curatf and rehabilitative so that the elderly can stay healthy. The sports activities at PSTW Budi Luhur Jambi carry out activities held once a week, but the physical condition of the elderly increasingly decreases, it is necessary to do an activity that will move the elderly to have a healthier life, through gymnastics programs for ages. The method of implementation is carried out by examining breathing and pulse before and after carrying out activities by recording their identity (name, age, gender). This activity was held on November 16, 2016, the location of the activity was held in Jambi Paradise tourist site. The results of this activity are respiratory and pulse examinations before and after performing a 15-minute leisurely activity. 10 people (30.3\%) had normal breathing, while 9 pulse (30\%) had a normal pulse. Examination of breathing and pulse after doing activity obtained results of respiratory calculations as many as 4 people (13.3\%) had normal breathing, while the pulse examination as many as 5 people (17\%) had a normal pulse.Decreased physical ability of the elderly due to deterioration in the function of the heart and lungs, it is better that physical activity be adjusted to the conditions and physical abilities of the elderly.
\end{abstract}

Keywords: Increased Elderly Health, Training Program, Elderly Gymnastic

\begin{abstract}
ABSTRAK
Upaya Kesehatan lanjut usia merupakan upaya kesehatan paripurna dasar dan menyeluruh dibidang kesehatan usia lanjut yang meliputi peningkatan kesehatan, pencegahan, pengobatan dan pemulihanagar lanjut usia dapat tetap sehat. Aktivitas olahraga di PSTW Budi Luhur Jambi melakukan kegiatan dilaksanakan 1 minggu sekali, namun keadaan fisik lansia kian hari kian menurun, maka perlu dilakukan suatu kegiatan yang akan menggerakkan lansia untuk memiliki hidup yang lebih sehat, melalui program senam untuk lajut usia.Metode pelaksanaan yang dilakukan dengan cara pemeriksaan pernafasan dan nadi sebelum dan setelah melakukan aktivitas dengan mencatat identitasnya (nama, umur, jenis kelamin). Kegiatan ini dilaksanakan pada tanggal 16 November 2016, lokasi kegiatan dilaksanakan di tempat wisata Jambi Paradise. Hasil kegiatan ini adalah Pemeriksaan pernafasan dan nadi sebelum dan sesudah melakukan aktivitas jalan santai 15 menit didapatkan 10 orang $(30,3 \%)$ memiliki pernafasan normal, sedangkan pemeriksaan nadi sebanyak 9 orang ( $30 \%)$ memiliki nadi normal. Pemeriksaan pernafasan dan nadi setelah melakukan aktivitas didapatkan hasil perhitungan pernafasan sebanyak 4 orang $(13,3 \%)$ memiliki pernafasan normal, sedangkan pemeriksaan nadi sebanyak 5 orang ( $17 \%)$ memiliki nadi normal. Berkurangnya kemampuan fisik lansia disebabkan kemunduran fungsi organ jantung dan paruparunya, sebaiknya aktivitas fisik disesuaikan dengan kondisi dan kemampuan fisik lanjut usia.
\end{abstract}

Kata Kunci : Peningkatan Kesehatan Lanjut Usia, Program Pelatihan, Senam Lansia Bugar 


\section{PENDAHULUAN}

Peningkatan kondisi sosial masyarakat dan usia harapan hidup (UHH) menyebabkan jumlah lanjut usia ( lansia) semakin berambah (Utomo 2009). Peningkatan UHH di Indonesia dari 68,6 tahun menjadi 70,8 tahun dan proyeksi tahun 2030-2035 mencapai 72,2 tahun (Kemenkes RI, 2016).Peningkatan jumlah lansia tersebut perlu mendapatkan perhatian masyarakat maupun tenaga profesional karena lansia beresiko mengalami berbagai gangguan kesehatan khususnya penyakit degeneratif, untuk itu diperlukan program peningkatan derajat kesehatan lansia agar dampak negatif dari tingginya UHH di Indonesia dapat dikurangi.

Gangguan kesehatan tersebut dapat menyebabkan penurunan kualitas hidup pada lansia. Salah satu cara yang dapat dilakukan dengan memeperbaiki pola hidup dalah dengan melakukan latihan fisik secara teratur (Setiawan, dkk 2012). Latihan fisik yang sesuai dengan lansia adalah senam lansia. Senam dapat meningkatkan aktivitas metabolik tubuh dan kebutuhan oksigen, oleh karena itu senam lansia sangat penting untuk para lanjut usia karena dapat menjaga kesehatan tubuh mereka

Upaya kesehatan usia lanjut adalah upaya kesehatan paripurna dasar dan menyeluruh dibidang kesehatan lansia yang meliputi peningkatan kesehatan, pencegahan, pengobatan dan pemulihan. Tempat pelayanan kesehatan tersebut bisa dilaksanakan di puskesmas, rumah sakit serta panti jompo dan tempat institusi lainnya.(Depkes RI, 2016)

Peranserta masyarakat dalam upaya mengoptimalkan kesehatan usia lanjut adalah sebagai pemberi pelayanan kesehatan maupun penerima pelayanan masalah lanjut usia baik di keluarga, panti jompo, rumah sakit maupun di masyarakat dalam bentuk pelaksanaan pembinaan dan pengembangan upaya kesehatan lanjut usia . (Kemenkes RI, 2013)

Tujuan pembinaan kesehatan lanjut usia adalah meningkatkan derajat kesehatan dan mutu kehidupan untuk mencapai masa tua yang bahagia dan berdayaguna dalam kehidupan lansia sesuai dengan keberadaannya dalam strata kemasyarakatan (Depkes RI, 2003)

Panti Sosial Tresna Werdha (PSTW) Budi Luhur merupakan panti jompo yang ada di Jambi, menampung lanjut usia denganj jumlah Lanjut usia sebanyak 73 orang.

Pembinaan kesehatan lanjut usia diharapkan akan menumbuhkan kemampuan lansia sendiri untuk mengatasi masalah kesehatan dengan dukungan dan bimbingan tenaga profesional, menuju terwujudnya kehidupan lansia yang sehat.Adapun program PSTW Budi Luhur Jambi dalam meningkatkan kesehtan lansia yaitu menyediakan fasilitas kesehatan dipanti dengan 1 orang perawat, melakukan pemeriksaan kesehatan setiap bulan di puskesmas setempat, dan melaksanakan program rekreasi setiap 3 bulan sekali. Namun yang bisa aktif melaksanakan kegiatan rekreasi ini hanya 30 orang lansia oleh karena itu pengabdian masyarakat ini di fokuskan pada lansia yang mengikuti rekreasi karena dianggap sehat secara fisik.

Program senam lansia di PSTW Budi Luhur Jambi sudah dilaksanakan sesuai jadwal yang ditentukan yakni 1 minggu sekali, namum peserta senam lansia yang mengikutinya kurang dari 30 orang, hal ini dikarenakan kemampuan fisik lansia mengalami keterbatasan. Untuk itu lansia di PSTW Budi Luhur Jambi direkomendasikan untuk melakukan aktivitas fisik minimal 15 -30 menit pada intensitas sedang setiap hari dalam seminggu, seperti berjalan, membersikan kamar.

Berdasarkan permasalahan tersebut, dapat diketahui tidak maksimalnya pembinaan kesehatan lansia di PSTW Budi 
Luhur Jambi dikarena keterbatasan fisik lansia. Pengabdian masyarakat ini memberikan fokus pengabdian masyarakat dalam mengoptimalkan pembinaan kesehatan lansia sehingga terbentuk pelayanan kesehatan yang sesuai dengan kebutuhan lansia diawali latihan fisik dengan intensitas ringan bertahap ke latihan fisik aktivitas sedang melalui program senal lansia

\section{TARGET DAN LUARAN}

Program pengabdian masyarakat ini khalayak sasarannya adalah lanjut usia PSTW Budi Luhur Jambi yang di kategorikan mampu secara fisik untuk melakukan olahraga/ aktivitas fisiklansia.

Target dan luaran tercapai setelah pelaksanaan pengabdian masyarakat ini 60\% lanjut usia di PSTW Budi Luhur Jambi mampu melakuakan olahraga senam lansia pasif dan $80 \%$ melakuakn aktivitas dengan intensitas sedang dengan melakukan senam lansia aktif secara rutin tiap minggunya.

Luaranyang ditargetkan dari pada pengabdian masayarakat ini adalah booklet senam lansia aktif maupun pasif yang dibutuhkan lanjut usia, Modul mata kuliah keperawatan gerontik

\section{METODE PELAKSANAAN}

Metode pelaksanaan yang dilakukan dengan cara pemeriksaan pernafasan dan nadi sebelum dan setelah melakukan aktivitas dengan mencatat identitasnya (nama, umur, jenis kelamin), untuk mengetahui kemampuan aktivitas lansia. Setelah itu memberikan penyuluhan dan mempraktekkan senam lansia aktif dan pasif pada lansia di PSTW Budi Luhur Jambi

Kegiatan ini dilaksanakan pada tanggal 16 November 2016 lokasi kegiatan dilaksanakan di tempat wisata Jambi Paradise. Diawali dengan pemeriksaan pernafasan dan nadi lansia diukur sebelum aktivitas (jalan santai) dan sesudah melakukan aktivitas jalan jantai selama 15 menit

\section{HASIL DAN PEMBAHASAN}

Kegiatan Pengabdian masyarakat dengan melakukan pemeriksaan pernafasan dan nadi sebelum dan sesudah melakukan aktivitas jalan santai selama 15 menit. Peserta yang mengikuti kegiatan ini sebanyak 30 orang lansia PSTW Budi Luhur Jambi yang masih dikategorikan mampu secara fisik, dengan jumlah lakilaki sebanyak 14 orang dan perempuan 16 orang. Rentang usia peserta yang mengikuti pengabdian masyarakat ini adalah 62-70 tahun.

Tabel 1. Data Lansia berdasarkan Usia

\begin{tabular}{cc}
\hline Umur & Jumlah \\
\hline $62-66$ & 14 \\
$67-71$ & 9 \\
$72-76$ & 7 \\
Total & 30 \\
\hline
\end{tabular}

Dari hasil pencatatan pemeriksaan pernafasan dan nadi sebelum melakukan aktivitas dengan jalan santai 15 menit didapatkan hasil perhitungan pernafasan sebanyak 10 orang $(30,3 \%)$ memiliki pernafasan normal, sedangkan pemeriksaan nadi sebanyak 9 orang (30\%) memiliki nadi normal.

Hasil pemeriksaan pernafasan dan nadi selah melakukan aktivitas didapatkan hasil perhitungan pernafasan sebanyak 4 orang $(13,3 \%)$ memiliki pernafasan normal , sedangkan pemeriksaan nadi sebanyak 5 orang ( $17 \%$ ) memiliki nadi normal.

Hasil penelitian Faridah (2013) Pengaruh program latihan lari jarak menengah dan interval training terhadap aktivitas enzim superoksida dismutase (SOD) menunjukkan bahwa tidak terjadinya 
penurunan superoksida dismutase (SOD) pada latihan fisik lari jarak menengah (lari 1600 meter) dan latihan fisik interval training (lari sprint $4 \times 400$ meter). Hal ini menunjukkan bahwa terjadinya adaptasi metabolik pada mahsiswa Bina Darma kota Palambang karena disamping nara coba adalah peserta extrakulikuler dan latihan yang dilakukan secara teratur sehingga akan terjadi beberapa perubahan otot dan sistem energi. Penelitian ini membuktikan bahwa latihan yang teratur dapat bermanfaat bagi tubuh manusia.

Senam aerobic lowimpact merupakan suatu aktivitas fisik aerobik yang bermanfaat untuk meningkatkan dan mempertahankan kesehatan dan daya tahan jantung, paru, peredaran darah otot dan sendi, Senam ini dapat dilakukan dengan frekuensi latihan 3-5 kali dalam seminggu dan dengan lama latihan 20-60 menit dalam satu kali latihan (Harber \& Scoot, 2009). Oleh karena itu diharapkan kepada lanjut usia tetap melakukan aktivitas mulai dari aktivitas ringan secara bertahap agar terjadi adaptasi fisologis peredaran darah lansia .

Semakin bertambahnya usia kemampuan jantung untuk memompakan darah keseluruh tubuh semakin berkurang, hal ini dapat dipantau dengan mengukur pernafasan dan nadi lansia. Pada kegiatan pengabdian ini, didapatkan data sebagai berikut

Gambar 1 Jumlah Lansia yang Pernafasan dan Nadi Normal berdasarkan jenis kelamin

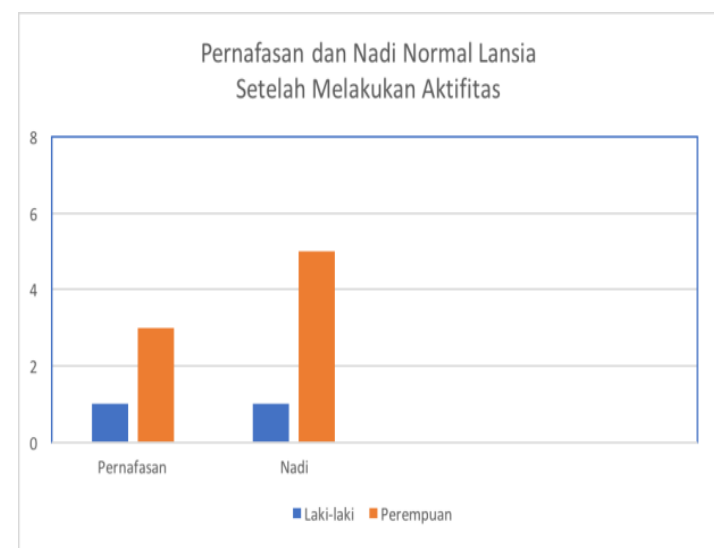

Nilai kapasitas vital pria dewasa lebih tinggi $20-25 \%$ daripada wanita dewasa hal ini disebabkan oleh perbedaan kekuatan otot pria dan wanita. Nilai kapasitas vital paru juga mempengaruhi oleh karakteristik umur, tinggi badan dan berat badan (Guyton \& Hall, 2011)

Adanya perbedaan hasil pengabdian masyarakat ini dengan referensi, kemungkinan disebabkan oleh populasi yang tidak merata, oleh karena itu diperlukan pengabdian lanjutan.

Menurut Novarina (2012)Olahraga pada lanjut usia dapat dilakukan dengan memperhatikan tingkat kekuatan fisik lansia seperti jalan cepat, bersepeda santai dan senam. Bahkan aktivitas sehari-hari seperti membersihkan kamar, rumah, berkebun, mencuci pakain dengan intensitas 30 menit juga baik bagi kesehatan lansia. Penting bagi lansia untuk mengikuti senam karena akan membantu tubuh lansia agar tetap sehat dan bugar, karena senam lansia membantu tulang agar tetap kuat, mendorong jantung bekerja secara optimal dan membantu menghilangkan radikal bebas yang terdapat didalam tubuh. Semua jenis senam dan aktivitas olagraga ringan sangat bermanfaat untuk menghambat proses degeneratif atau proses penuaan. Berdasarkan artikel yang dipublikasikan oleh Better Heath Channel (2011) yang berjudul Healthy aging-stay physically active, menyatakan bahwa olahraga dapat membantu lansia menjaga kemandirian, 
sembuh dari penyakit dan mengurangi resiko penyakit (Better Heath Channel 2011). Olahraga yang cocok untuk lansia adalah senam, yang dikenal dengan senam lansia. Senam lansia merupakan serangkaian gerakan yang teratur dan terarah serta terencana yang dilakukan dengan maksud meningkatkan kemampuan fungsional tubuh. Senam lansia yaitu olahraga ringan atau mudah dilakukan dan tidak memberatkan untuk dilakukan dan diterapkan pada lansia. Olah raga ini membantu tubuh agar bugar dan mencapai kesehatan yang optimal dan membantu menghilangkan radikal bebas didalam tubuh, sehingga lansia dapat melakukan aktivitas sehari-hari secara mandiri. Ada beberapa manfaat senam baik secara fisiologis, psikologis maupun sosial. Manfaat senam secara fisiologis yaitu meningkatkan dan memelihara tonus otot, kekuatan otot, fleksibelitas sendi, keseimbangan dan koordinasi gerak. Secara Psikologis tentunya menciptakan perasaan senang, fungsi kognitif dan kesehatan jiwa, secara sosial meliputi peningkatan integritas sosial dan kultur, keterpaduan, pemberdayaan usia lanjut dan hubungan ketidak setiakawanan sosial (Depkes RI, 2013).

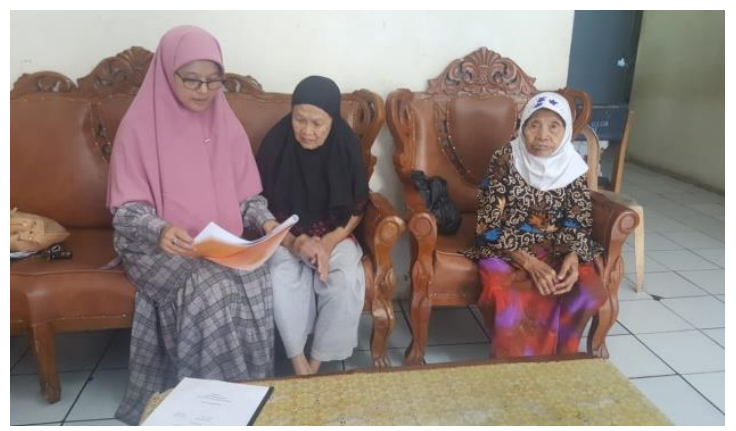

Gambar 2. Sosialisasi Program Senam Lansia

\section{KESIMPULAN DAN SARAN}

\section{Kesimpulan}

Pemeriksaan pernafasan dan nadi sebelum melakukan aktivitas jalan santai diperlukan untuk menentukan kemampuan lansia untuk melakukan olahraga yang sesuai dengan kemampuan fisiknya Keegiatan ini diikui 30 orang lansia PSTW Budi Luhur Jambi

Selah melakukan aktivitas jalan santai didapatkan hasil perhitungan pernafasan sebanyak 4 orang $(13,3 \%)$ memiliki pernafasan normal, sedangkan pemeriksaan nadi sebanyak 5 orang ( $17 \%$ ) memiliki nadi normal.

\section{Saran}

Lansia dengan usia lebih dari 65 tahun disarankan melakukan olahraga tidak terlal kualitas hidupu membebani tulang seperti berjalan, senam lansia. Bagi lansia yang tidak terlatih harus dimulai dengan intensitas rendah

Aktivitas fisik bagi lansia sebaiknya disesuaikan dengan kondisi dan kemampuan fisik masing-masing

\section{UCAPAN TERIMAKASIH}

Pengabdian masyarakat ini dapat terwujud dan selesai dengan baik karena adanyabantuan dari berbagai macam pihak maka dari itu penulis mengucapkan terima kasih kepada Ketua STIKES Baiturrahim Jambi, Kaprodi D-III keperawatan STIKES Baiturrahim Jambi, pimpinan PSTW Budi Luhur Jambiyang telah memfasilitasi kegiatan pengabdian masyarakat ini.

\section{DAFTAR PUSTAKA}

Departemen Kesehatan Republik Undonesia (2016). Pusat Promosi Kesehatan. Jakarta

Guytpn, 2013, Fisiologi manusia edisi XII .Jakarta. EGC

Faridah (2013). Pengaruh Lari Jarak Menengah dan Interval Training terhadap Aktifitas Enzim 
superoksida dismutase (SOD) ,Tesis,Universitas Sriwijaya.

Harber.P.M., \& Scoot, T (2009). Aerobic Exercise Training Improves Wholemuscle and Single Miofiber size and Function in older woment. Journal Physical Reguler Integral Company Physical

Kementrian Kesehatan Republik Indonesia (2016). Situasi Lanjut Usia di Indonesia. Jakarta : Pusat Data dan Informasi. Kemenkes RI

Setiawan G.W. Herlina. I.S.W dan Damajanti H.C.P (2013) Pengaruh Lansia terhadap Kualias Hidup Penderita Hipertensi. Fakultas Kedokteran. Universitas Samratulang Manado.

Utomo B. (2010). Hubungan antara kekuatan otot dan Daya Tahan Otot Anggota Gerak Bawah dengan Kemampuan Fungsional Lansia. Tesis. Surakarta. Universitas Sebelas Maret 